\title{
RETÓRICA DA AGUDEZA NUM SONETO DE D. FRANCISCo MANUEL DE MELO
}

\author{
Thiago César Viana Lopes Saltarelli
}

Doutorando em Letras

\section{RESUMO}

A partir da consulta aos principais tratados de retórica e de poética do século 17, buscase uma definição da agudeza, um dos elementos mais significativos da poética seiscentista, e dá-se um exemplo de seu emprego num soneto de D. Francisco Manuel de Melo.

\section{PALAVRAS-CHAVE}

Retórica, poética, agudeza, D. Francisco Manuel de Melo

No primeiro capítulo da obra El discreto, Baltasar Gracián discorre sobre a faculdade do ingenio, a qual, segundo o jesuíta, pertence à “esfera do entendimento”. ${ }^{1}$ Isso significa que ela é responsável pelo uso da inteligência de forma racional e esclarecida, concretizando o que na esfera do genio era apenas inclinação. Sebastián de Covarrubias também dá uma definição do engenho no seu Tesoro de la lengua castellana o española: "Força natural do entendimento investigadora do que por razão e discurso se pode alcançar em todo gênero de ciências, disciplinas, artes liberais e mecânicas, sutilezas, invenções e enganos.” ${ }^{2}$ Temos aí duas ideias importantes: a de que o engenho é força natural e que opera pela razão e pelo discurso. Isso significa que, por um lado, ele seria algo espontâneo, idiossincrático, próprio de alguns indivíduos, por assim dizer, eleitos para serem engenhosos. Por outro lado, a sua forma de expressão pertence ao domínio do lógos e configura uma tékhne, uma ars, e portanto pode ser ensinada, aprendida e exercitada.

É justamente o ensino dessa ars ingenii aquilo que Baltasar Gracián pretende prescrever na obra Agudeza y arte de ingenio. Observamos a permanência do fundamento “técnico” do engenho no próprio título da obra, que reitera a estreita relação entre arte e

\footnotetext{
${ }^{1}$ GRACIÁN. Obras completas. Estudio preliminar, edición y notas de Arturo del Hoyo, p. 78-81.

${ }^{2}$ Citado por GRACIÁN Obras completas. Estudio preliminar, edición y notas de Arturo del Hoyo, p. 78. (tradução minha).
} 
engenho. Segundo o tratado, uma das habilidades dessa força natural do entendimento é comparar as coisas e encontrar semelhanças entre elas. Ora, este não é senão o princípio da metáfora, e não por acaso ela é a figura retórica considerada mais importante por Emanuele Tesauro, em seu tratado Cannocchiale aristotelico:

E eis-nos, por fim, chegados grau por grau ao mais alto cume das Figuras Engenhosas: diante das quais todas as outras Figuras até aqui citadas perdem o valor: sendo a METÁFORA o mais engenhoso e agudo; o mais raro e admirável; o mais jovial e vantajoso; o mais eloqüente e fecundo parto do humano intelecto. (...) Engenhosíssimo, certamente: pois que, se o engenho consiste (como dissemos) no ligar e unir as noções remotas e separadas dos objetos propostos, este é propriamente o ofício da Metáfora, e não de alguma outra figura (...). ${ }^{3}$

Contudo, nem todas as comparações possuem o mesmo grau de clareza. Algumas são mais óbvias, outras mais inusitadas. Estas se expressam de forma também mais inusitada do que aquelas, e, portanto, exigem maior capacidade do engenho. Assim, a faculdade suprema do engenho consiste em encontrar relações inesperadas e artificiosas entre conceitos distantes. Isto é propriamente a essência da agudeza, assim definida por Gracián: “Consiste, pois, este artifício conceituoso em uma primorosa concordância, em uma harmônica correlação entre dois ou três cognoscíveis extremos, expressa por um ato do entendimento.” ${ }^{4}$ Logo, podemos dizer que a agudeza é, “quase sempre, uma expansão do discurso para zonas laterais e inesperadas de significação”. 5 Ainda segundo Hansen, na elocução aguda, “o intervalo semântico entre a noção abstrata ou conceito e a metáfora que a representa exteriormente pode ser maior ou menor - quanto maior for o intervalo, maior a novidade da combinação de coisas já conhecidas”. ${ }^{6}$ Um excelente exemplo que ilustra essas definições encontra-se num soneto anônimo presente no terceiro volume da Fênix renascida, o qual traz a seguinte definição de papagaio na primeira estrofe:

Iris parlero, Abril organizado,

Ramillete de plumas con sentido,

Hybla com habla, irracional florido.

\footnotetext{
${ }^{3}$ TESAURO. Il Cannocchiale aristotelico, p. 266. (tradução minha).

${ }^{4}$ GRACIÁN. Obras completas. Estudio preliminar, edición y notas de Arturo del Hoyo, p. 239. (tradução minha).

${ }^{5}$ HANSEN. Retórica da agudeza, p. 324. (tradução minha).

${ }^{6}$ HANSEN. Retórica da agudeza, p. 324. (tradução minha).
} 
Primaveras con piem, jardin alado. ${ }^{7}$

Aqui, o intervalo semântico entre o conceito que se quer designar - papagaio - e as metáforas que o representam - é extremamente largo. Tomando como exemplo uma dessas metáforas, por exemplo, abril, observamos que o processo de sua identificação com o conceito de papagaio se dá por um extenso percurso analógico, durante o qual se descobrem similitudes entre grupos de cognoscíveis. Assim, temos que a noção de abril é análoga à de primavera, pois esta é a estação do ano vigente nesse mês na Europa. A noção de primavera, por sua vez, é análoga à de algo florido e muito verde, uma vez que essa estação é a época de esplendor das plantas. O próximo passo na cadeia analógica identifica a noção de verde $e$ florido com as plumas verdes e coloridas do papagaio, ave que certamente, no século 17, chamava a atenção nas cortes europeias pela novidade e extravagância. Finalmente, então, temos a cadeia de similitudes que permite ligar os conceitos a priori tão distantes de abril e papagaio. Além disso, a palavra papagaio não aparece uma só vez em todo o poema. Esse é um extremo do raciocínio agudo, pelo qual fica a cargo do leitor descobrir o termo original da comparação.

Com base na tipologia das agudezas estabelecidas por Gracián, podem-se apreender duas dimensões que operam na formulação de uma agudeza: em primeiro lugar, uma dimensão dialética, que decompõe os conceitos para estabelecer semelhanças e diferenças entre eles; em segundo lugar, uma dimensão retórica, responsável por dar expressão e ornamentar a comparação dos conceitos. Tais dimensões devem sempre andar juntas na elaboração das agudezas, conforme esclarece Gracián: “Atende a dialética à conexão de termos, para formar bem um argumento, um silogismo; e a retórica ao ornato de palavras, para compor uma flor eloqüente, que é um tropo, uma figura.”8 Se compararmos esse preceito com a definição que nos dá Matteo Peregrini sobre a essência da agudeza, veremos que para o tratadista italiano também é indispensável encontrar aí as duas dimensões mencionadas:

(...) para investigar internamente a natureza das agudezas admiráveis, discorro deste modo: em uma sentença não é outra coisa senão palavras, objetos significados e a sua recíproca ligação. As palavras, assim como os objetos ou coisas isoladamente consideradas, são pura matéria: então a agudeza se rege necessariamente pela ligação. Esta se pode considerar entre

\footnotetext{
${ }^{7}$ Citado por CIDADE. A poesia lírica cultista e concepstista, p. 19.

${ }^{8}$ GRACIÁN. Obras completas. Estudio preliminar, edición y notas de Arturo del Hoyo, p. 238. (tradução minha).
} 
palavras e palavras, entre coisas e palavras, entre coisas e coisas, e em cada uma destas maneiras pode ser artificiosa ou, ainda, sem artifício. ${ }^{9}$

Peregrini é incisivo ao afirmar que a agudeza se rege necessariamente pela ligação entre as coisas ou as palavras, uma vez que estas, sozinhas, são pura matéria sem produção de sentido ou efeito retórico. A ligação entre elas é, pois, estabelecida pela dialética, que as analisa para descobrir as suas semelhanças e diferenças. Essa faculdade de captar as possíveis identidades entre dois ou até mais conceitos em princípio distantes é denominada por Tesauro de perspicácia. Esse procedimento, como informa Peregrini, pode ser expresso com ou sem artifício, mas só esse último interessa ao campo de estudo da agudeza:

(...) a agudeza pressupõe-se como uma coisa artificiosa. O artifício, porque há de trazer à luz o admirável, não deverá ser comum, mas grandemente raro; e porque há de formar um objeto visível altamente aprazível ao intelecto, a sua raridade e virtude se explicarão em apresentar uma disposição recíproca e conveniente entre as partes artificiosamente ligadas na sentença (...). ${ }^{10}$

Logo, nas expressões e ditos agudos, é preciso que haja artifício e que este seja raro e surpreendente. Tesauro denomina de versatilidade a capacidade de apropriação do código retórico-poético disponível para criar uma expressão aguda, que transmita de modo eficiente e agradável a engenhosa analogia de conceitos distantes. Assim, concluímos que a perspicácia e a versatilidade (nos termos de Tesauro), a ligação e o artificío (nos termos de Peregrini), enfim, a dialética e a retórica são faculdades, elementos e dimensões imprescindíveis à expressão da agudeza. Pode-se dizer que, no século 17, a agudeza melhor se realiza pela interseção entre dialética, retórica e poesia.

Essa interseção permite identificarmos procedimentos agudos em todas as etapas do processo retórico, desde o raciocínio conceituoso da inventio até as soluções inusitadas da elocutio, como se observa neste soneto de D. Francisco Manuel de Melo:

Rubi $\left(\mathrm{A}_{1}\right)$, cujo valor não conhecido( $\left.\mathrm{B}_{1}\right)$

Foi, do vil lapidário a quem foi dado;

Diamante $\left(\mathrm{A}_{2}\right)$ que, quando mais guardado,

Dentre as mãos de seu dono foi perdido $\left(\mathrm{B}_{2}\right)$;

Zafiro $\left(A_{3}\right)$ singular, que foi vendido $\left(B_{3}\right)$

A quem em ferro o tem mal engastado;

Aver $\left(\mathrm{A}_{4}\right)$ que, por se haver em vão achado,

\footnotetext{
${ }^{9}$ PEREGRINI. Delle acutezze, p. 30. (tradução minha)

${ }^{10}$ PEREGRINI. Delle acutezze, p. 30. (tradução minha)
} 
Em pastas de carvão foi convertido $\left(\mathrm{B}_{4}\right)$;

Pérola $\left(A_{5}\right)$ sem igual, pouco estimada

Do bárbaro boçal, índio inorante

Por quem acaso foi do mar levada $\left(\mathrm{B}_{5}\right)$,

Sois na fortuna, mas dessemelhante

No valor, se ante vós não valem nada

Zafir $\left(A_{3}\right)$, pérola $\left(A_{5}\right)$, aver $\left(A_{4}\right)$, rubi $\left(A_{1}\right)$, diamante $\left(A_{2}\right) .{ }^{11}$

Há nesse poema um artificioso procedimento de dispositio de seus elementos, sobretudo daqueles que guardam semelhanças entre os conteúdos designados por sua expressão lógica e gramatical. Esse procedimento faz parte de um grupo de possibilidades de organização dos elementos textuais desenvolvido pela Retórica medieval e muito explorado pela poesia de Góngora. A esses procedimentos Dámaso Alonso dá o nome de tática dos conjuntos semelhantes. ${ }^{12}$ Vejamos então como se organiza a dispositio dos conjuntos desse poema.

Como mostra a ementa, nesse soneto o poeta lamenta o casamento de uma dama com um homem que não lhe valoriza devidamente, e o faz dirigindo-se à dama e comparando-a com alguns elementos aos quais a cultura atribui valor. Assim, temos um sujeito vós, no décimo terceiro verso, que representa a dama, a quem o poeta se dirige; o verbo de ligação sois, no início do décimo segundo verso; e uma série de predicativos atribuídos à dama pelo poeta, que é o que mais nos interessa. Esses predicativos - rubi, diamante, zafiro (safira), aver (tesouro, riqueza) e pérola - encontram-se disseminados ao longo dos quartetos e do primeiro terceto. Formam, então, nos termos de Dámaso Alonso, uma pluralidade $A_{1}, A_{2}, A_{3}, A_{4}, A_{5}$, em que o elemento A designa o conteúdo conceitual genérico da primeira pluralidade, ou seja, todos os seus cinco elementos têm em comum o fato de serem objetos de valor na tradição cultural europeia do século 17 e de exercerem a função sintática de predicativo do sujeito vós dentro do poema.

Cada um desses elementos, segundo o poeta, sofreu algum revés da fortuna e passou a um estado de infortúnio. Tal condição é expressa por orações adjetivas que caracterizam os objetos predicativos da dama. Cada oração adjetiva possui um verbo na voz passiva - (não) ser conhecido, ser perdido, ser vendido, ser convertido, ser levado - que indica o fato sucedido com os objetos da primeira pluralidade. Cria-se, então, uma segunda pluralidade $\mathrm{B}_{1}$,

\footnotetext{
${ }^{11}$ MELO. A tuba de Calíope: quarta musa das Obras métricas. Introdução, estabelecimento do texto, notas e glossário por Segismundo Spina, p. 231. (tradução minha)

${ }^{12}$ ALONSO.Tácticas de los conjuntos semejantes, p. 49-81. (tradução minha)
} 
$\mathrm{B}_{2}, \mathrm{~B}_{3}, \mathrm{~B}_{4}, \mathrm{~B}_{5}$, cujo conteúdo conceitual genérico $\mathrm{B}$ designa a ação sofrida pelos objetos de valor. No esquema dispositivo desse soneto, os elementos de ambas as pluralidades $\left(A_{n}\right.$ e $\left.B_{n}\right)$ se combinam formando conjuntos - expressão lógica e gramatical de um fenômeno ${ }^{13}$ (- de dois sintagmas, apresentados paralelisticamente. Os quatro primeiros conjuntos $\left(A_{1} B_{1} ; A_{2} B_{2}\right.$; $\left.A_{3} B_{3} ; A_{4} B_{4}\right)$ vêm apresentados nos quartetos, cada um ocupando dois versos. O quinto conjunto $\left(A_{5} B_{5}\right)$ aparece no primeiro terceto. Temos, então, a seguinte ordenação paralelística:

\footnotetext{
$>\quad \mathrm{A}_{1} \mathrm{~B}_{1}$ : [Vós sois] rubi [cujo valor] (não) foi conhecido.

$>\quad \mathrm{A}_{2} \mathrm{~B}_{2}$ : [Vós sois] diamante [que] foi perdido.

$>\quad \mathrm{A}_{3} \mathrm{~B}_{3}$ : [Vós sois] zafiro [que] foi vendido.

$>\quad \mathrm{A}_{4} \mathrm{~B}_{4}$ : [Vós sois] aver [que] foi convertido [em carvão].

$>\quad A_{5} B_{5}$ : [Vós sois] pérola [que] foi levada. Essa flecha poderia encurtar-se!
}

No último terceto, os cinco conjuntos convergem para a oração principal, constituindo, como dissemos, os predicativos do sujeito vós, a ele atribuídos pelo verbo de ligação sois. A dama, portanto, é rubi, diamante, zafiro, aver e pérola - note-se, aqui, a aproximação entre cognoscíveis extremos -, pois compartilha a sua má fortuna. Ela foi “vendida” e "levada” por um homem que, tão ignorante quanto os proprietários daqueles tesouros, não soube valorizar o bem que possui.

Entretanto, se, em relação à fortuna, a dama se assemelha aos objetos valiosos, no que tange ao valor de cada um, estes valem muito menos do que ela. D. Francisco constrói, então, uma outra oração, que encerra o soneto, para transmitir essa ideia. Os objetos que foram comparados à dama e que haviam sido disseminados ao longo do poema são agora recolhidos no último verso, que reagrupa os elementos da primeira pluralidade e os ordena de forma paratática, ou seja, alinhados no mesmo verso: “zafir, pérola, aver, rubi, diamante”. A fórmula geral da ordenação dos conjuntos semelhantes nesse soneto seria, então, a seguinte:

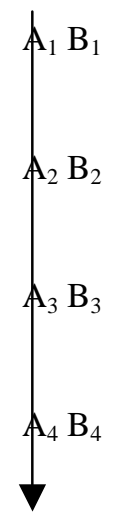

\footnotetext{
${ }^{13}$ Cf. ALONSO. Tácticas de los conjuntos semejantes, p. 52.
} 
Podemos afirmar que as táticas de ordenação de conjuntos semelhantes são uma joia da agudeza da dispositio, explorada no máximo limite pela poesia seiscentista. Dentre as várias táticas ou procedimentos possíveis, o que espalha elementos ao longo do poema para recolhê-los no final é um dos mais produtivos e característicos das letras do século 17, não apenas na poesia como também na prosa, sendo denominado de diseminativo-recolectivo (ou simplesmente disseminação e recolha) por Dámaso Alonso. ${ }^{14}$ Sua utilização por D. Francisco Manuel de Melo revela o autor como um dos mais característicos artistas de sua época.

\section{RÉSUMÉ}

À partir de la consultation des principaux traités de rhétorique et de poétique du dizième siècle, on cherche une définition de la pointe, un des éléments les plus significatifs de la poétique de ce siècle, et on donne un exemple de son emploi dans un sonnet de D. Francisco Manuel de Melo.

\section{MOTS-CLÉ}

Rhétorique, poétique, pointe, D. Francisco Manuel de Melo

\section{REFERÊNCIAS}

ALONSO, Dámaso. Tácticas de los conjuntos semejantes. In: literária española. 2. ed. aum. e corr. Madrid: Gredos, 1956. p. 49-81.

CARVALHO, Maria do Socorro Fernandes de. Poesia de agudeza em Portugal. 2006. Tese (Doutorado em Letras). Universidade Estadual de Campinas, IEL-UNICAMP, Campinas, 2004.

CIDADE, Hernani. A poesia lírica cultista e concepstista. 4. ed. corr. e ampl. Lisboa: Seara Nova, 1968.

GRACIÁN, Baltasar. Obras completas. Estudio preliminar, edición y notas de Arturo del Hoyo. 2. ed. Madrid: Aguilar, 1960.

HANSEN, João Adolfo. Retórica da agudeza. Letras Clássicas - Revista do Departamento de

\footnotetext{
${ }^{14}$ ALONSO.Tácticas de los conjuntos semejantes, p. 63-66.
} 
Letras Clássicas da USP, São Paulo, n. 4, p. 317-342, jun. 2000.

HANSEN, João Adolfo. Barroco, neobarroco e outras ruínas. Teresa - Revista de Literatura Brasileira, São Paulo, n. 2, p. 10-66, jan. 2001.

MELO, D. Francisco Manuel de. A tuba de Calíope: quarta musa das Obras métricas. Introdução, estabelecimento do texto, notas e glossário por Segismundo Spina. São Paulo: Brasiliense/Edusp, 1988.

PEREGRINI, Matteo. Delle acutezze. Torino: RES, 1997. (Collezione di retorica, 4).

TESAURO, Emanuele. Il Cannocchiale aristotelico. Savigliano: L’Artistica Piemontese, 2000. (Edição Fac-Similar). 